\title{
STRATEGI PENGELOLAAN LINGKUNGAN EKOWISATA DI SUBAK JATILUWIH KECAMATAN PENEBEL KABUPATEN TABANAN
}

\author{
Gusti Ngurah Kama Wijaya ${ }^{1 *}$, Made Antara ${ }^{2)}$, Wayan Windia ${ }^{3)}$ \\ 1) Unit Layanan Pengadaan Barang/Jasa dilingkungan Pemerintah Provinsi Bali, Denpasar \\ 2) Fakultas Pertanian Universitas Udayana, Denpasar \\ 3) Fakultas Pertanian Universitas Udayana, Denpasar \\ *Email: ngurah_im3@yahoo.com
}

\begin{abstract}
Subak Jatiluwih in 2012 has been named as one of the World Heritage nomination from UNESCO. The level of tourist visits to Subak Jatiluwih continues to increase each year. The rate of environmental damage due the development of tourism is also expected to increase, and therefore need to be efforts to minimize environmental damage from tourism development. This study aims to identify the potential of ecotourism in Subak Jatiluwih, knowing how to manage the environment at the moment and assess environmental management strategies ecotourism, so that tourism development is carried out to provide benefits not only to the social and economic fields surrounding communities but also to the preservation of the environment in Subak Jatiluwih.

The approach used in this study is a qualitative approach. The method of collecting data in this study using the observation, interviews and questionnaires. The data obtained were analyzed by descriptive qualitative analysis equipped with IFAS (Internal Factor Analysis Summary), EFAS (Exsternal Factor Analysis Summary), SWOT (Strength Weakness Opportunities Threats) analysis and QSPM (Quantitative Strategies Planning Matrixs) analysis to determine strategic priorities has been produced.

Based on the observation the environmental potential of ecotourism in Subak Jatiluwih is abiotic potential consisting of rice field panorama, Besi Kalung Temple panorama, wellsprings, waterfall, hot springs, river. Biotic potential include brown rice, Kokokan bird. Social and cultural potentials include the existence of subak organization, technology used in water distribution system, myth, potential of 13 traditional ceremonies conducted in Subak Jatiluwih. The results of SWOT analysis, there are four strategies that is Strength Opportunities Strategy (SO), Strength Threats Strategy (ST), Weaknesses Opportunities Strategy (WO) and Weaknesses Threats Strategy (WT). Each of these strategies are translated into programs in environmental management of ecotourism in Subak Jatiluwih. QSPM analysis results a functional strategy with highest scale priority to be implemented is the development of tour packages based on agriculture, culture and nature.

Ecotourism environmental management in Subak Jatiluwih requires completeness of supporting facilities and infrastructures such as improved roads, irrigation channels, parking and toliet. In addition to support of the empowerment local communities should reduce the use of migrants labor and involve local communities especially members of Subak as a tour guide, forming subak cooperatives and perform packaging of agriculturebased tourism, culture and nature, by limiting the number of tourists visit if its felt beyond the carrying capacity.
\end{abstract}

Kata Kunci: Ecotourism; Environmental Management; QSPM; Subak; SWOT

\section{PENDAHULUAN}

Subak Jatiluwih adalah salah satu subak yang terletak di Desa Jatiluwih Kecamatan Penebel Kabupaten Tabanan yang terkenal dengan keindahan panorama alam pegunungan dan pemandangan persawahan yang indah. Pada tahun 2012 Subak Jatiluwih yang merupakan bagian dari Catur Angga Batukaru menerima status sebagai Warisan Budaya Dunia dari UNESCO (Windia dan Wiguna, 2013). Jumlah kunjungan wisatawan ke Subak Jatiluwih dari tahun ke tahun terus menunjukkan peningkatan (Disparda Provinsi Bali,
2014). Meningkatnya tingkat kunjungan wisatawan membawa pengaruh terhadap pengembangan dan pembangunan di Subak Jatiluwih. Laju kerusakan lingkungan yang disebabkan pengembangan pariwisata diperkirakan akan meningkat. Tingginya potensi kerusakan lingkungan di Subak Jatiluwih harus dapat diminimalisir dengan strategi kelestarian lingkungan, yaitu melalui kegiatan dan pengembangan ekowisata (Ecotourism). Ekowisata merupakan suatu konsep pariwisata yang berwawasan lingkungan, mengikuti kaedah keseimbangan dan kelestarian lingkungan (Wood, 2002). Penelitian ini bertujuan untuk mengetahui 
potensi dan kendala pengelolaan lingkungan ekowisata di Subak Jatiluwih, mengetahui bagaimana pengelolaan lingkungan ekowisata di Subak Jatiluwih saat ini dan mengetehui bagaimana strategi pengelolaan lingkungan ekowisata di Subak Jatiluwih di masa mendatang, sehingga pengembangan pariwisata yang dilakukan dapat memberikan manfaat bukan hanya pada bidang sosial dan ekonomi masyarakat sekitar namun juga kepada pelestarian lingkungan di Subak Jatiluwih.

\section{METODOLOGI}

Penelitian ini termasuk penelitian eksploratif dimana penelitian ini bertujuan untuk mengekplorasi potensi dan kendala pengelolaan lingkungan ekowisata serta merumuskan strategi pengelolaan ekowisata di Subak Jatiluwih sehingga dapat menjawab tantangan bagaimana pariwisata dapat berkontribusi secara nyata terhadap kelestarian lingkungan dan masyarakat sekitar. Metoda pengumpulan data dalam penelitian ini adalah observasi, wawancara, angket dan dokumentasi. Narasumber yang dilibatkan dalam penelitian mempunyai kompetensi dalam bidang pengelolaan potensi ekowisata di Subak Jatiluwih. Analisis data dilakukan dengan metode deskriptif kualitatif, sedangkan untuk analisis strategi pengelolaan lingkungan ekowisata dilakukan dengan IFAS (Internal Factor Analysis Summary), EFAS (Exsternal Factor Analysis Summary), Matrik IFAS dan EFAS, analisis SWOT (Strength Weakness Opportunities Threats), serta Analisis QSPM (Quantitative Strategiws Planning Matrik) digunakan untuk menentukan rangking dari strategi yang telah ditetapkan.

\section{HASIL DAN PEMBAHASAN}

\subsection{Kondisi Lingkungan Subak Jatiluwih}

Subak Jatiluwih terletak pada ketinggian antara 750-1500 mdpl. Morfologi lahan di Kawasan Jatiluwih merupakan daerah perbukitan dan pegunungan di mana terdapat empat gunung berdekatan yaitu Gunung Batukaru, Gunung Sanghyang, Gunung Pohen dan Gunung Adeng. Permukaan tanah Kawasan Jatiluwih tersusun oleh formasi geologi yang beragam. Batuan yang lebih muda adalah tufa dan endapan lahar Buyan-Bratan dan Batur yang terbentuk pada era kuarter. Kondisi klimatologi Kawasan Jatiluwih mempunyai iklim tropis dengan curah hujan rata-rata cukup tinggi. Suhu rata-rata di Kawasan Jatiluwih mencapai $27^{\circ} \mathrm{C}$ dengan suhu terendah $24^{\circ} \mathrm{C}$ dan suhu tertinggi $30^{\circ} \mathrm{C}$. Kelembaban udara berkisar antara $74-77 \%$ dan curah hujan tahunan rata-rata berkisar $2.155-3.292 \mathrm{~mm}$. Tipe hujan dicirikan dengan turunnya hujan bermusim dilanjutkan dengan musim kemarau. Berdasarkan kondisi iklim dan curah hujan tersebut masyarakat di Desa Jatiluwih banyak yang mengembangkan kegiatan pada bidang pertanian dan perkebunan.

Luas Subak Jatiluwih \pm 348 ha dan terbagi atas tujuh sub subak atau tempek yaitu Umakayu, Gunung Sari, Telabah Gede, Kedamaian, Kesambi, Besi Kalung dan Umadui. Sumber air irigasi di Subak Jatiluwih didapat dari mata air, air terjun dan beberapa sungai yang melintasi Subak Jatiluwih seperti Sungai Yeh Ho, Sungai Yeh Baat, Sungai Munduk Abangan dan Sungai Yeh Pusut. Subak Jatiluwih dipimpin oleh seorang pekaseh dan masingmasing tempek dipimpim oleh klian tempek. Anggota Subak Jatiluwih bukan hanya berasal dari Desa Jatilwuih saja namun juga berasal dari berbagai desa di sekitar Desa Jatiluwih hingga ke Kecamatan Penebel.

\subsection{Potensi dan Kendala Pengelolaan Lingkungan Ekowisata di Subak Jatiluwih \\ Potensi lingkungan ekowisata yang ada di Subak} Jatiluwih terbagi atas tiga bagian utama yaitu potensi abiotik yang terdiri dari 1) Potensi panorama persawahan, 2) Potensi panorama Pura Luhur Besi Kalung, 3) Potensi mata air, 4) Potensi air terjun, 5) Potensi air panas, 6) Potensi sungai, 7) Potensi jalur cycling dan 8) Potensi jalur tracking. Potensi biotik meliputi 1) Potensi beras merah, 2) Potensi burung Kokokan. Potensi sosial budaya meliputi 1) Keberadaan organisasi subak, 2) Teknologi sistem pembagian air yang digunakan, 3) Potensi mitos, 4) Potensi 13 upacara adat yang dilakukan di Subak Jatiluwih. Dalam pengembangan potensi lingkungan ekowisata di Subak Jatiluwih terdapat beberapa kendala yang dapat menghambat yaitu 1) Kendala sarana, prasarana jalan dan selokan, 2) Kendala air dan saluran irigasi, 3) Kendala parkir, 4) Kendala pencemaran dari peternakan ayam, 5) Kedala longsor, 6) Kendala SDM dan Motivasi, dan 7) Kendala kebijakan.

\subsection{Pengelolaan Lingkungan Ekowisata di Subak Jatiluwih pada saat ini}

Gambaran pengelolaan lingkungan ekowisata di Subak Jatiluwih pada saat ini dilakukan dengan membandingkan antara kondisi di lapangan pada saat ini dengan kondisi ideal sesuai teori pengelolaan yang terdiri dari empat tahap yaitu perencanaan, pengorganisasian, pelaksanaan dan evaluasi (Tery dalam Burhanudin, 2009). Pada kondisi eksisting Pemerintah Kabupaten Tabanan pada bulan Pebruari 2013 telah membentuk badan pengelola, susunan dan kesepakatan serta perjanjian kerjasama antar semua stake holder. Badan pengelola ini selanjutnya membentuk Manajemen Operasional DTW Jatiluwih, oleh karena itu pada kondisi sekarang sudah ada mekanisme pengelolaan potensi yang dilakukan, namun pengelolaan tersebut baru bersifat 
pembentukan badan pengelola beserta manajemenya, tarif retribusi, persentase pembagian hasil retribusi, visi, misi organisasi, dan implementasi personil. Terdapat beberapa tahap pengelolaan yang belum dilakukan seperti pengamatan lingkungan, pelatihan, penentuan strategi dan kebijakan maupun evaluasi kinerja, hal tersebut dikarenakan Badan Pengelola DTW Jatiluwih beserta struktur organisasi manajemen operasional DTW Jatiluwih tersebut baru terbentuk sekitar dua tahun.

\subsection{Strategi Pengelolaan Lingkungan Ekowisata di Subak Jatilwuih}

Penentuan strategi pengelolaan lingkungan ekowisata di Subak Jatiluwih dimulai dengan melakukan pengamatan lingkungan internal meliputi kekuatan dan kelemahan dan faktor eksternal meliputi peluang dan ancaman. Setelah dijabarkan faktor internal dan faktor eksternal langkah selanjutnya adalah melakukan pembobotan dan peratingan terhadap masing-masing faktor. Hasil rata-rata pembobotan dan peratingan dari narasumber untuk faktor internal seperti ditunjukkan Tabel 1.

Analisis faktor internal (IFAS) pada Tabel 1 menghasilkan kekuatan dengan bobot tertinggi adalah aktifitas anggota subak yang sarat akan budaya dan berwawasan lingkungan. Sedangkan untuk faktor kelemahan kerusakan saluran irigasi dan berkurangnya debit sumber air yang menyebabkan lahan persawahan rentan mengalami kekeringan memiliki bobot tertinggi. Faktor kekuatan dengan rating tertinggi adalah adanya lahan persawahan bertingkat yang indah. Faktor kelemahan dengan rating tertinggi adalah kurangnya fasilitas penunjang pariwisata seperti parkir dan toilet umum. Hasil rata-rata pembobotan dan peratingan dari narasumber untuk faktor eksternal seperti ditunjukkan Tabel 2.

Hasil rata-rata pembobotan dan peratingan dari narasumber untuk faktor eksternal (EFAS) pada Tabel 2 menunjukkan peluang dengan bobot tertinggi adalah status Subak Jatiluwih sebagai warisan budaya dunia dari UNESCO, sedangkan faktor ancaman dengan bobot tertinggi adalah serangan hama seperti wereng dan tikus yang dapat merusak tanaman padi. Faktor peluang dengan rating tertinggi ditempati oleh dua faktor sekaligus yaitu status Subak Jatiluwih sebagai Warisan Budaya Dunia dari UNESCO dan merupakan pengembangan pariwisata yang berwawasan lingkungan dan budaya. Faktor ancaman dengan rating tertinggi adalah adanya persaingan antar daerah tujuan wisata yang memiliki kesamaan potensi.

Hasil penjumlahan perkalian antara bobot dan rating untuk masing-masing faktor internal (IFAS) menghasilkan nilai 2,957, sedangkan hasil penjumlahan perkalian antara bobot dan rating untuk masing-masing faktor eksternal (EFAS) menghasilkan nilai 2,673, hal tersebut memposisikan strategi umum yang digunakan pada matrik IFAS dan EFAS adalah strategi pada sel V yaitu strategi

Tabel 1. Internal Factor Analysis Summary (IFAS)

\begin{tabular}{|c|c|c|c|c|}
\hline & Kekuatan & Bobot & Rating & $\begin{array}{l}\text { Bobot } x \\
\text { Rating }\end{array}$ \\
\hline a. & Adanya awig-awig yang berwawasan lingkungan. & 0,068 & 3,143 & 0,214 \\
\hline b. & Memiliki lahan persawahan bertingkat yang indah. & 0,071 & 3,571 & 0,255 \\
\hline c. & Memiliki sumber mata air alami dan air terjun. & 0,063 & 3,429 & 0,216 \\
\hline d. & Memiliki varietas beras merah unggulan yang sudah terkenal. & 0,044 & 2,857 & 0,127 \\
\hline e. & Sudah memiliki lembaga pengelola. & 0,083 & 3,000 & 0,250 \\
\hline f. & Terdapat jalur trecking dan cycling yang cukup memadai. & 0,071 & 3,000 & 0,214 \\
\hline \multirow[t]{2}{*}{ g. } & Aktifitas anggota subak yang sarat akan budaya dan berwawasan lingkungan. & 0,097 & 3,143 & 0,306 \\
\hline & Kelemahan & Bobot & Rating & $\begin{array}{l}\text { Bobot } x \\
\text { Rating }\end{array}$ \\
\hline a. & $\begin{array}{l}\text { Kerusakan saluran irigasi dan berkurangnya debit sumber air menyebabkan lahan } \\
\text { persawahan rentan mengalami kekeringan. }\end{array}$ & 0,083 & 2,857 & 0,239 \\
\hline b. & $\begin{array}{l}\text { Topografi wilayah dengan tingkat kemiringan yang cukup tinggi dan kondisi curah hujan } \\
\text { yang tinggi bepotensi menyebabkan longsor. }\end{array}$ & 0,056 & 2,571 & 0,145 \\
\hline c. & Minimnya kualitas SDM terutama dalam penguasan bahasa asing. & 0,063 & 2,714 & 0,171 \\
\hline d. & Kurangnya fasilitas penunjang pariwisata seperti parkir dan toilet umum. & 0,078 & 3,143 & 0,246 \\
\hline e. & $\begin{array}{l}\text { Pengelolaan potensi subak belum maksimal (kebanyakan wisatawan hanya melihat } \\
\text { pemandangan sawah dari pinggir jalan utama). }\end{array}$ & 0,071 & 2,571 & 0,184 \\
\hline f. & Kondisi jalan menuju Subak Jatiluwih yang kurang memadai. & 0,070 & 2,857 & 0,199 \\
\hline g. & Konflik penggunaan air baik antar sesama anggota subak, dengan pemerintah dan swasta. & 0,078 & 2,429 & 0,190 \\
\hline \multicolumn{2}{|c|}{ JUMLAH } & 1,000 & & 2,957 \\
\hline
\end{tabular}


Tabel 2. Exsternal FactorAnalysis Summary (EFAS)

\begin{tabular}{|c|c|c|c|c|}
\hline & Peluang & Bobot & Rating & $\begin{array}{l}\text { Bobot } x \\
\text { Rating }\end{array}$ \\
\hline a. & Status Subak Jatiluwih sebagai warisan budaya dunia dari UNESCO. & 0,092 & 3,286 & 0,303 \\
\hline b. & Perubahan paradigma terhadap kegiatan wisata berbasis lingkungan yang cenderung meningkat. & 0,073 & 2,857 & 0,210 \\
\hline c. & Merupakan pengembangan pariwisata yang berwawasan lingkungan dan budaya. & 0,087 & 3,286 & 0,286 \\
\hline d. & Kebijakan pemerintah pusat untuk swasembada pangan. & 0,058 & 2,429 & 0,141 \\
\hline e. & $\begin{array}{l}\text { Perubahan paradigma terhadap bahan makanan organik terutama beras dan beras merah } \\
\text { yang cenderung meningkat. }\end{array}$ & 0,048 & 2,571 & 0,123 \\
\hline f. & $\begin{array}{l}\text { Banyak sumber dana yang secara tidak langsung mengarah pada pengembangan kepariwisataan } \\
\text { seperti perbaikan lingkungan. }\end{array}$ & 0,080 & 2,571 & 0,206 \\
\hline \multirow[t]{2}{*}{ g. } & $\begin{array}{l}\text { Harga paket ekowisata yang ditawarkan berpeluang terus meningkat karena berhubungan } \\
\text { dengan kepuasan wisatawan dan kelengkapan fasilitas penunjang. }\end{array}$ & 0,060 & 2,571 & 0,154 \\
\hline & Ancaman & Bobot & Rating & $\begin{array}{l}\text { Bobot } x \\
\text { Rating }\end{array}$ \\
\hline a. & $\begin{array}{l}\text { Adanya persaingan antar daerah tujuan wisata yang memiliki kesamaan potensi seperti ubud, } \\
\text { payangan dan lain sebagainya. }\end{array}$ & 0,075 & 3,000 & 0,226 \\
\hline b. & $\begin{array}{l}\text { Perubahaan dan ketidakpastian musim yang dapat menyebabkan kekeringan dan musim } \\
\text { hujan berkepanjangan. }\end{array}$ & 0,075 & 2,571 & 0,193 \\
\hline c. & Banyaknya peternakan ayam di sekitar subak yang dapat menyebabkan pencemaran. & 0,061 & 2,429 & 0,149 \\
\hline d. & Meningkatnya kunjungan wisatawan akan meningkatkan alih fungsi lahan. & 0,070 & 2,571 & 0,180 \\
\hline e. & Kebijakan pemerintah yang belum jelas. & 0,070 & 2,571 & 0,180 \\
\hline f. & Minimnya pendapatan petani dari mengelola sawah. & 0,068 & 2,000 & 0,136 \\
\hline \multirow[t]{2}{*}{ g. } & Serangan hama seperti wereng dan tikus yang dapat merusak tanaman padi. & 0,082 & 2,286 & 0,188 \\
\hline & JUMLAH & 1,000 & & 2,673 \\
\hline
\end{tabular}

pertumbuhan melalui integrasi horisontal dengan berkonsentrasi pada kegiatan usaha yang sekarang dilakukan dan memperluas kegiatan-kegiatan, menambah dan mengembangkan rentang produk dan jasa yang ditawarkan (Hunger dan Wheelen, 2003).

Setelah mendapatkan strategi umum pengelolaan lingkungan ekowisata di Subak Jatiluwih, strategi tersebut kemudian dijabarkan menjadi empat strategi induk melalui analisis SWOT yaitu strategi strengths opportunities (SO), strategi strengths threats (ST), strategi weaknesses opportunities (WO) dan strategi weaknesses threats (WT). Tiap-tiap strategi tersebut kemudian dijabarkan menjadi beberapa strategi fungsional yang mencerminkan strategi induknya. Strategi SO dijabarkan menjadi 1) Pengelolaan lingkungan ekowisata berbasis pertanian, budaya dan alam, 2) Menciptakan beras merah sebagai brand Subak Jatiluwih, 3) Memaksimalkan kinerja lembaga pengelola dan menjalin kerjasama dengan instansi atau stakeholder terkait, 4) Meningkatkan partisipasi anggota subak dalam pengawasan pelaksanaan awig-awig dan peraturan perundang undangan. Strategi ST dijabarkan menjadi 1) Memperkenalkan keunikan potensi alam Subak Jatiluwih dan beras merah, 2) Memperkuat awigawig tentang pengelolaan lingkungan atau perda RTRW, 3) Pemberdayaan anggota subak dalam pengelolaan potensi, dan 4) Pengendalian dan penanggulangan hama secara terpadu. Strategi WO dijabarkan menjadi 1) Peningkatan kualitas lingkungan, sarana prasana pertanian, saluran irigasi dan fasilitas penunjang pariwisata, 2) Peningkatan ketrampilan dan kualitas SDM, 3) Peningkatan produksi beras merah organik. Strategi WT dijabarkan menjadi 1) Pendataan potensi bencana longsor dan kerusakan saluran irigasi serta pemantauan debit sumber air, 2) Menjalin kerjasama antara pengusaha peternakan ayam dan anggota subak, 3) Pemanfaatan anggota subak dalam pembangunan sarana dan prasarana penunjang, 4) Sosialisasi peraturan mengenai jalur hijau dan pemberian insentif bagi jalur hijau serta pengenaan jasa lingkungan. Setelah menentukan strategi fungsional dalam pengelolaan lingkungan ekowisata di Subak Jatiluwih, masing-masing strategi fungsional tersebut kemudian dijabarkan menjadi beberapa program kerja dalam pengelolaan lingkungan ekowisata di Subak Jatiluwih. Penjabaran program kerja tersebut harus mencerminkan strategi fungsionalnya.

Tahap terakhir dalam penentuan strategi pengelolaan lingkungan ekowisata di Subak Jatiluwih adalah menentukan skala prioritas dari masing-masing strategi yang telah ditetapkan. Penentuan skala prioritas dilakukan dengan analisis Quantitative Strategies Planning Matrixs (QSPM). 
Tabel 3. Jumlah nilai total ketertarikan (Total Attractive Score/TAS) untuk tiap-tiap strategi

\begin{tabular}{llc}
\hline & Strategi Strength Opportunities (SO) & Jumlah TAS \\
\hline 1. & Pengelolaan lingkungan ekowisata berbasis pertanian, budaya dan alam & 7,143 \\
2. & Menciptakan beras merah sebagai brand Subak Jatiluwih & 5,714 \\
3. & Memaksimalkan kinerja lembaga pengelola dan menjalin kerjasama dengan instansi atau stakeholder terkait & 5,714 \\
4. & Meningkatkan partisipasi anggota subak dalam pengawasan pelaksanaan awig-awig dan peraturan perundang undangan & 6,571 \\
\hline & Strategi Strength Threats (ST) & Jumlah TAS \\
\hline 1. & Memperkenalkan keunikan potensi alam subak jatiluwih dan beras merah & 6,571 \\
2. & Memperkuat awig-awig tentang pengelolaan lingkungan atau perda RTRW & 6 \\
3. & Pemberdayaan anggota subak dalam pengelolaan potensi & 6 \\
4. & Pengendalian dan penanggulangan hama secara terpadu & 6 \\
\hline & Strategi Weaknesses Opportunities (WO) & Jumlah TAS \\
\hline 1. & Peningkatan kualitas lingkungan, sarana prasana pertanian, saluran irigasi dan fasilitas penunjang pariwisata. & 6,571 \\
2. & Peningkatan ketrampilan dan kualitas SDM & 6,857 \\
3. & Peningkatan produksi beras merah organik & 5,714 \\
\hline & Strategi Weaknesses Threats (WT) & Jumlah TAS \\
\hline 1. & Pendataan potensi bencana longsor dan kerusakan saluran irigasi serta pemantauan debit sumber air. & 6 \\
2. & Menjalin kerjasama antara pengusaha peternakan ayam dan anggota subak. & 5,143 \\
3. & Pemanfaatan anggota subak dalam pembangunan sarana dan prasarana penunjang. & 5,571 \\
4. & Sosialisasi peraturan mengenai jalur hijau dan pemberian insentif bagi jalur hijau serta pengenaan jasa lingkungan. & 5,714 \\
\hline
\end{tabular}

Analisis QSPM dimulai dengan merumuskan nilai ketertarikan masing-masing narasumber (Attractive Score/AS) terhadap sejumlah strategi yang telah dirumuskan. Langkah selanjutnya adalah menentukan nilai total ketertarikan (Total Attractive Score/TAS), yaitu dengan mengalikan bobot masingmasing faktor pada analisis IFAS dan EFAS dengan nilai rata-rata ketertarikan dari narasumber (Attractive Score/AS). Jumlah nilai total ketertarikan (Total Attractive Score/TAS) untuk masing-masing strategi seperti ditunjukan pada Tabel 3.

Jumlah nilai total ketertarikan (Total Attractive Score/TAS) masing-masing strategi pada analisis QSPM menunjukkan bahwa strategi dengan TAS tertinggi adalah pengelolaan lingkungan ekowisata berbasis pertanian, budaya dan alam dengan nilai 7,143. Tingginya TAS pada suatu strategi menunjukkan bahwa strategi ini memiliki prioritas utama untuk direalisasikan dibandingkan strategistrategi lainnya. Selain hal tersebut tingginya TAS pada strategi pengelolaan lingkungan ekowisata berbasis pertanian, budaya dan alam, karena narasumber mengganggap strategi ini sesuai dengan karakteristik ekowisata yang lebih bertanggung jawab secara lingkungan dan alam, memberikan kontribusi yang positip terhadap konservasi lingkungan dan budaya setempat, sehingga pengelolaan lingkungan ekowisata di Subak Jatiluwih diharapkan mampu melestarikan sumber daya alam, lingkungan dan budaya setempat.

\section{SIMPULAN DAN SARAN}

\subsection{Simpulan}

1. Potensi lingkungan ekowisata yang ada di Subak Jatiluwih yang dapat dikembangkan menjadi daya tarik ekowisata terbagi atas tiga bagian utama yaitu potensi abiotik yang terdiri dari 1) Potensi panorama persawahan, 2) Potensi panorama Pura Luhur Besi Kalung, 3) Potensi mata air, 4) Potensi air terjun, 5) Potensi air panas, 6) Potensi sungai 7). Potensi jalur cycling 8) Potensi jalur tracking. Potensi biotik yaitu 1) Potensi beras merah dan 2) Potensi Burung Kokokan. Potensi sosial budaya yaitu 1) Keberadaan organisasi subak, 2) Teknologi sistem pembagian air yang digunakan, 3) Potensi mitos, 4) Potensi 13 upacara adat yang dilakukan di Subak Jatiluwih. Kendala-kendala dalam pengelolaan lingkungan ekowisata di Subak Jatiluwih yaitu 1) Kendala sarana, prasarana jalan dan selokan, 2) Kendala air dan saluran irigasi, 3) Kendala parkir, 4) Kendala pencemaran dari peternakan ayam, 5) Kedala longsor, 6) Kendala SDM dan Motivasi, dan 7) Kendala kebijakan.

2. Pada kondisi eksisting Pemerintah Kabupaten Tabanan sudah membentuk Badan Pengelola dan Manajemen Operasional DTW Jatiluwih yang bertugas mengelola potensi wisata yang ada, mengatur retribusi di Jatiluwih dan besaran 
pembagiannya, mengatur perjanjian kerjasama, implementasi personil baik sebagai tenaga administrasi maupun tenaga kebersihan lingkungan, terdapat beberapa tahap pengelolaan yang belum dilakukan seperti pengamatan lingkungan baik internal maupun eksternal, pelatihan personil, penentuan strategi dan kebijakan serta evaluasi kinerja.

3. Strategi umum yang tepat diterapkan adalah strategi pertumbuhan melalui integrasi horisontal dengan berkonsentrasi pada kegiatan usaha yang sekarang dilakukan dan memperluas kegiatan-kegiatan, menambah dan mengembangkan rentang produk dan jasa yang ditawarkan. Strategi tersebut kemudian dijabarkan kedalam strategi induk yang terdiri atas strategi SO, strategi ST, strategi WO dan strategi WT. Strategi dengan nilai prioritas tertinggi adalah Strategi SO yaitu pengelolaan lingkungan ekowisata berbasis pertanian, budaya dan alam. Strategi-strategi yang sudah dirumuskan tersebut kemudian dijabarkan kembali menjadi beberapa program yang mencermikan strategi induknya.

\subsection{Saran}

Saran bagi Pemerintah

1. Mengkaji ulang besaran prosentase pembagian hasil retribusi agar dapat memberikan porsi yang lebih besar terhadap subak, anggota subak dan masyarakat setempat.

2. Pengelolaan lingkungan ekowisata di Subak Jatiluwih membutuhkan kelengkapan sarana dan prasana penunjang seperti perbaikan kondisi jalan, saluran irigasi, parkir dan toliet umum.

3. Memberikan insentif atau penghapusan pajak bumi dan bangunan pada petani pemilik sawah yang masih bertani.

4. Melakukan sosialisasi peraturan tentang tata ruang dan jalur hijau.

Saran bagi Badan Pengelola dan Manajemen Operasional

1. Pengelolaan lingkungan ekowisata di Subak Jatiluwih hendaknya mengurangi tenaga kerja pendatang dan melibatkan masyakat lokal terutama anggota subak.

2. Melakukan evaluasi kinerja dan penggunaan anggaran agar anggaran yang ada dapat dimanfaatkan untuk program-program yang berguna bagi kelestarian budaya dan lingkungan di Subak Jatiluwih.

3. Melakukan pengelolaan lingkungan berbasis pertanian, budaya dan alam, dengan membatasi jumlah kunjungan wisatawan jika dirasa melampaui daya dukung.

Saran bagi anggota subak

1. Membentuk koperasi untuk menjual hasil subak dan memenuhi kebutuhan petani.

2. Menjalin kerjasama dengan pengusaha peternakan ayam di sekitar Subak Jatiluwih.

3. Menambah wawasan dan ilmu khususnya bahasa asing dan pemenuhan kebutuhan wisatawan.

\section{DAFTAR PUSTAKA}

Anonim. 2015. Perkembangan Jumlah Kunjungan Wisatawan pada Daya Tarik Wisata di Bali Tahun 2003-2014. Avaiable from: http:// www.disparda.baliprov.go.id/id/Statistik2, diakses 21 Juni 2014.

Burhanudin. 2009. Manajemen Aset Daerah, Edisi Pertama. Bogor: Pusdiklatwas BPKP.

Hunger, J. David dan Wheelen, Thomas L. 2003. Manajemen Strategis. Yogyakarta: Penerbit ANDI.

Windia, Wayan dan Wiguna, Wayan Alit Artha. 2013. Subak Warisan Budaya Dunia. Denpasar: Udayana University Press.

Wood, Megan Epler. 2002. Ecotourism: Principles, Practices and Policies For Sustainability. France: Division of Technology, Industry and Economics, United Nations Environment Programme (UNEP). Avaiable from: http:// www.uneptie.org/tourism/home.html. 